\title{
Market Opportunities for Animal-Friendly Milk in Different Consumer Segments
}

\author{
Sophie de Graaf ${ }^{1,2,3, *}$, Filiep Vanhonacker ${ }^{1,4}$, Ellen J. Van Loo ${ }^{1}$, Jo Bijttebier ${ }^{2}$, \\ Ludwig Lauwers ${ }^{1,2}$, Frank A. M. Tuyttens ${ }^{3}$ and Wim Verbeke ${ }^{1}$ \\ 1 Department of Agricultural Economics, Faculty of Bioscience Engineering, Ghent University, 9000 Ghent, \\ Belgium; Filiep.Vanhonacker@ugent.be (F.V.); Ellen.VanLoo@ugent.be (E.J.V.L.); \\ Ludwig.lauwers@ilvo.vlaanderen.be (L.L.); Wim.Verbeke@ugent.be (W.V.) \\ 2 Social Sciences Unit, Institute for Agricultural and Fisheries Research (ILVO), 9820 Merelbeke, Belgium; \\ Jo.Bijttebier@ilvo.vlaanderen.be \\ 3 Animal Sciences Unit, Institute for Agricultural and Fisheries Research (ILVO), 9090 Melle-Gontrode, \\ Belgium; Frank.Tuyttens@ilvo.vlaanderen.be \\ 4 Department of Applied Biosciences, Faculty of Bioscience Engineering, Ghent University, \\ 9000 Ghent, Belgium \\ * Correspondence: sophie.degraaf@ugent.be; Tel.: +32-9-272-2609
}

Academic Editor: Gerrit Antonides

Received: 29 September 2016; Accepted: 7 December 2016; Published: 11 December 2016

\begin{abstract}
Consumers have increasing, but highly variable, interest in sustainability attributes of food, including ethical aspects, such as animal welfare. We explored market opportunities for animal-friendly cow's milk based on segmentation (cluster) analysis. Flemish survey participants ( $n=787)$ were clustered $(n=6)$ based on their intention to purchase (IP) animal-friendly milk, and their evaluation of cows' welfare state (EV). Three market opportunity segments were derived from clusters and labelled as "high", "moderate" and "limited". Only 8\% of the participants belong to the "high market opportunities" segment, characterized by a high IP and a low EV. The "limited" segment $(44 \%)$ indicated a neutral to low IP and a positive EV. The "moderate" segment ( $48 \%)$ had a moderately positive IP and positive/negative EV. Reported willingness to pay, interest in information about the state of animal welfare and importance of the product attribute "animal welfare" differed among segments and were strongly related to IP. Most promising selling propositions about animal-friendly milk were related to pasture access. The high degree of differentiation within the Flemish milk market reveals market opportunities for animal-friendly milk, but for an effective market share increase supply of animal-friendly products needs to get more aligned with the heterogeneous demand.
\end{abstract}

Keywords: animal welfare; consumers; dairy cattle; ethical consumption; market segmentation; milk; survey

\section{Introduction}

The public is increasingly interested in sustainability aspects of food consumption, including the various characteristics of the production process and of the final food products themselves. For the livestock production, these concerns also imply the more ethical dimension such as animal welfare $[1,2]$. However, although European citizens report high levels of concern in relation to farm animal welfare [3], the market for animal-friendly products—or of products that are commonly perceived as such-is small. For example, the market share of organic milk, which is associated with higher levels of animal welfare by consumers [4-6], was $2.7 \%$ in Belgium in 2015 [7]. This may illustrate that concerns do not always translate into purchase behaviour [8,9], called the "consumer-citizen-duality". While citizens are driven by moral concerns, consumers are driven by the product characteristics 
involved in their food purchasing decision process [10]. To account for this duality, it is important to take both consumer-related and citizen-oriented measures into consideration when studying this topic.

The European food market for premium animal welfare products is currently a niche market where differentiation levels in the products vary according to the farm animal species. Eggs, for example, have moderate differentiation (i.e., cage, barn eggs, free range, and organic), whereas cow's milk shows little differentiation in terms of animal welfare with the exception of welfare-related options such as "organic" (following EU Council Regulation No. 834/2007) and "access to pasture". The current market for animal-friendly products mostly attracts consumers with only one specific profile, while previous studies [11-14] demonstrated a more heterogeneous interest in farm animal welfare. Whilst some consumer clusters are highly interested in animal-friendly products, other clusters may consider animal welfare to be an important product attribute but not dominant to other product attributes such as price, taste or quality. For these consumers, products that compromise between animal welfare and price, termed "compromise products", "mildly sustainable products" or "medium welfare products" in different papers, may be an attractive alternative [14-17]. However, knowledge about market opportunities in different consumer clusters for specific types of animal(-derived) products is currently lacking.

Societal concern about animal welfare varies among species of farm animals [17] along with the degree of "feeling well-informed about welfare" [18]. In response, the current study focuses on dairy cattle with cow's milk as product, for several reasons. First, consumers do not want to be reminded of the living animal when it had to be killed for the product while purchasing meat (so-called "strategic ignorance" [19-21]). Hence, it is expectedly easier to communicate about the animal and its welfare for products, such as milk, that do not require the animal to be killed. A second advantage is that dairy farms strongly differ in the housing and management factors affecting cow welfare [22,23]. This makes it possible to differentiate the milk based on animal welfare status. Third, the dairy sector represents a significant proportion (15\%) of the EU agricultural output [24], and market differentiation might be a welcome strategy for this sector, which regularly faces economic crises and searches for overall sustainability.

The overall objective of this study is therefore, to explore market opportunities for animal-friendly milk by clustering individuals based on a consumer- and a citizen-oriented measure. The overall objective is further specified into three research goals. First, this study will identify consumer segments for animal-friendly milk. Second, it will be examined to what extent market opportunities exist within different consumer segments for animal-friendly milk in Flanders, Belgium. The specific focus on the region Flanders is motivated by the significance of the dairy sector in the study area itself and for milk production in Belgium. Third, the resulting segments will be profiled in terms of perceived attribute importance and interest in information as basis for the development of marketing and communication strategies for animal-friendly milk. These insights can support a targeted marketing approach, relevant to seize market opportunities.

\section{Materials and Methods}

A web-based questionnaire was completed in May 2014 by 827 consumers living in Flanders, the northern region of Belgium. Participants were recruited by a subcontracted professional market research agency. The sample was representative for the Flemish population in terms of age, regional distribution and gender (Table 1). As $44 \%$ of the participants had a university college or university degree, the sample was slightly biased towards higher educated people (which was $\pm 30 \%$ in the Flemish population in 2014), which is common in online surveys [25]. All respondents were involved in food purchasing (not necessarily the main person responsible). 
Table 1. Socio-demographic profile of the sample and the Flemish population.

\begin{tabular}{cccc}
\hline & Characteristics & Sample (\%) & Population a ${ }^{(\%)}$ \\
\hline \multirow{4}{*}{ Age } & $21-29$ & 17.5 & 18.3 \\
& $30-39$ & 23.1 & 24.3 \\
& $40-49$ & 24.7 & 25.8 \\
& $50-59$ & 21.9 & 21.7 \\
\multirow{3}{*}{ Regional distribution } & $60-65$ & 12.9 & 10.0 \\
\hline \multirow{3}{*}{ Gender } & Antwerp & 28.4 & 27.6 \\
& East Flanders & 23.9 & 22.9 \\
& West Flanders & 18.1 & 18.5 \\
& Flemish Brabant & 15.2 & 17.1 \\
& Limburg & 14.4 & 13.8 \\
\hline \multirow{2}{*}{ Education } & Female & 52.4 & 49.5 \\
& Male & 47.6 & 50.5 \\
\hline & Elementary education (6 years of schooling) & 4.6 & 15.7 \\
& Secondary education (12 years of schooling) & 51.8 & 54.9 \\
& University college (Bachelor's degree) & 33.1 & 14.8 \\
& University degree (Master's degree) & 10.5 & 14.5 \\
\hline
\end{tabular}

a Based on Belgian Federal Government Statistics for the Flemish population, 2012.

The survey consisted of four tiers of variables: (1) segmentation variables; (2) variables aimed to form a socio-demographic profile of the clusters; (3) variables used to examine market opportunities of the different clusters; and (4) measures aimed to support the market positioning of animal-friendly milk, mainly in terms of communication.

\subsection{Segmentation Variables}

The consumer-related measures used as segmentation variables were the intention to try and the intention to effectively purchase animal-friendly milk. These were measured with the statements "I am willing to buy animal-friendly milk from now on, instead of the milk I usually buy", and "I am willing to buy animal-friendly milk to try it" using a 5-point Likert scale ranging from "totally disagree" to "totally agree". The citizen-oriented measure was the perceived evaluation of the current state of dairy cattle welfare (EV), which was measured using the question "How would you rate the welfare of dairy cattle in Flanders?" on a 7-point scale ranging from "very bad" to "very good". The term "dairy cattle welfare" was not defined in the survey because there are varying definitions of animal welfare, among consumers [13] and even among animal scientists [26]. We wanted respondents to use their own perception of animal welfare, as they would do so as a consumer too.

\subsection{Socio-Demographics}

Age, regional distribution (Flemish provinces), gender and education were probed using categorical scales. Rural or urban living conditions, familiarity with agriculture and livestock were scored on 5-point semantic differential scales. The bipolar adjectives were "rural" /"urban", "not familiar at all with agriculture" /"very familiar with agriculture" and "not familiar at all with livestock" /"very familiar with livestock".

\subsection{Market Opportunities}

To determine market opportunities in Flanders, Belgium for animal-friendly milk among different consumer segments, we examined the different segments' milk consumption pattern, general attitudes towards milk and the milk processing industry, and willingness to pay for animal-friendly milk. 


\subsubsection{Milk Consumption}

Participants were asked about their milk consumption frequency and about the type of milk they usually buy. Options for frequency of milk consumption were: "multiple times per day", "every day", "multiple times per week", "once per week" or "less than once per week". For the type of milk, the main types present in the Belgian market were listed, including "organic" (following Council Regulation (EC) No. 834/2007), "fair trade" (indicates that farmers received a fair and higher price for their milk), "farm milk" (i.e., the whole process, from milking the cow to packaging the milk, is performed by the farmer), "AA-milk" (a Belgian quality label with specific hygiene requirements for farmers and milk processors), and "conventional milk" (defined as none of the above). Participants could also indicate "our family does not purchase milk", in which case they $(n=40)$ were excluded from the analysis (see inclusion criteria), resulting in 787 usable responses.

\subsubsection{General Attitudes towards Milk and Milk Processing Industry}

General attitudes towards milk and the milk industry were scored on 5-point semantic differential scales. For attitude towards milk, the bipolar adjectives were "unhealthy" /"healthy", "not essential" /"essential", "not tasty" /"tasty", "expensive" /"cheap", "old-fashioned" /"modern", and "negative" /"positive". For attitude towards the milk industry, the bipolar adjectives were "unjust" /"just", "negative" /"positive", "unsustainable" /"sustainable" and "not transparent" /"transparent".

\subsubsection{Willingness to Pay (WTP)}

WTP was measured using contingent valuation [27] using the question: "suppose that a label came onto the market that you trust which guarantees animal-friendly production of the milk. To which degree would you be willing to buy this product instead of a product without such a label?" This is a widely used method in consumer studies that is easily understood by participants. Despite limitations, e.g., relating to hypothetical bias, the contingent valuation method can yield valuable insight into eventual differences between consumer segments regarding WTP. Respondents were provided with a reference price of the current average conventional milk price in Belgian supermarkets (based on an online consultation of five Belgian supermarkets, $€ 1.10$ per litre). WTP for animal-friendly label milk was probed for different price points, including no change in price (€1.10 per litre) and for price increases of $5 \%$ ( $€ 1.16$ per litre), $10 \%$ ( $€ 1.21$ per litre), $20 \%$ ( $€ 1.32$ per litre), $50 \%$ ( $€ 1.65$ per litre) and $100 \%$ ( $€ 2.20$ per litre). Answers were on a 5-point scale ranging from "very unlikely" to "very likely".

\subsection{Communication about Animal-Friendly Milk}

To form the basis for development of marketing and communication strategies about animal-friendly milk, segments were profiled in terms of perceived attribute importance, trust in information sources, preferred format of information on dairy cattle welfare, and interest in information about dairy cattle welfare.

\subsubsection{Perceived Attribute Importance}

The perceived attribute importance was measured using the question: "When buying milk, how important are the following product attributes for you?" on a 5-point interval scale ranging from " 1 = totally unimportant" to " $5=$ very important". Based on Vanhonacker et al. [13], attributes included were: "quality", "food safety", "freshness", "health", "price", "packaging", "taste", "sustainability", "production method", "animal welfare", "local production", "country of origin", "environmental friendliness" and "fair trade"). 


\subsubsection{Trust in Information Sources and Preferred Format of Information on Dairy Cattle Welfare}

Respondents were asked to indicate their level of trust in different information sources in relation to dairy cattle welfare on a 5-point scale ranging from "a complete lack of trust" to "a great deal of trust". Sources were "government", "animal welfare organization", "supermarket", "milk processing sector", "farmer", "consumer organization", "science" and "veterinarian". Additionally, respondents were asked to indicate their preference towards five possible welfare labels on a 5-point scale ranging from "absolutely no preference" to "strong preference". Options were chosen to allow comparison between: (1) a general animal welfare label versus a specific animal welfare label; (2) a tangible animal welfare issue versus an intangible animal welfare issue (i.e., more difficult to imagine without having specific knowledge on dairy cattle) from the consumer point of view; and (3) a product label with a broader scope including animal welfare versus an animal welfare label. Therefore, options were "a general cow welfare label" (general animal welfare label), "a cow welfare label with a focus on access to pasture" (specific animal welfare label, tangible issue), "a cow welfare label with a focus on welfare problems such as udder infection and lameness" (specific animal welfare label, intangible issue), "a label with focus on sustainability, where higher animal welfare requirements are one aspect" (product label with a broader scope, including animal welfare) and "a label with a focus on local production, where higher animal welfare requirements is only one of the aspects" (product label with a broader scope, including animal welfare).

\subsubsection{Interest in Information about Dairy Cattle Welfare}

Respondents were probed about their interest in information about dairy cattle welfare using measures and criteria derived from the Welfare Quality ${ }^{\circledR}$ (WQ) protocol for dairy cattle [28]. This protocol describes methods to integrate dairy cattle welfare measures into 12 criteria, four principles and an overall welfare category. All 26 welfare measures and 11 of the 12 criteria were used in the current study (Appendix). In dairy cattle, the criterion "Thermal comfort" is not measured and was thus not included in the survey. The full WQ protocol for dairy cattle can be found at http:/ / www.welfarequalitynetwork.net/.

To measure interest in information, the following question was used for each WQ measure and criterion: "Several aspects that can influence the welfare of dairy cows are listed below. To what degree do you wish to be informed about each of these aspects in order to make the right choice when buying cow's milk?" Answers were on a 100-point scale ranging from "I do not want to be informed about this at all when I am buying cow's milk" to "This is very interesting information for me when I am buying cow's milk". Measures and criteria were shown separately and in random order to prohibit the respondents from scoring the measures purely based on the criteria they belong to.

\subsection{Statistical Analysis}

Factor Analysis using principal components was performed for both attitude measures. Items were excluded using backwards selection when factor scores were lower than 0.6 and when the item loaded high (greater than half of the highest) on two or more factors, as recommended by Field [29]. Internal consistency (using Cronbach's alpha's) was checked and deemed acceptable when higher than 0.7 following Nunnally [30]. Factor Analysis revealed that all descriptors for attitude towards milk loaded on one factor (total variance explained: $70.2 \%, \alpha=0.85$ ), except for the items "expensive versus cheap" and "old fashioned versus modern", which were removed because factor loadings were not high enough (0.43 and 0.57). The items of attitude towards the milk industry could all be fit into one factor (total variance explained: $73.2 \%, \alpha=0.88$ ). Because of the high Cronbach's alphas, a mean attitude score towards milk and the milk processing industry was calculated, by summating and averaging the respondents scores for the individual adjectives, and used in further analyses (bivariate analysis using one-way ANOVA). 
Data were analysed using SPSS 22 (Chicago, IL, USA). For the cluster analysis, first hierarchical clusters were developed using Ward's method. Subsequently, K-means cluster analyses were performed to obtain clusters (following [31]). Z-scores were used for all segmentation variables to get a better view of the relative position of the clusters. Bivariate analysis using one-way ANOVA with Dunnett's T3 post hoc comparison of mean scores and cross-tabulation with $\chi^{2}$-statistics were used to profile the clusters.

\section{Results}

\subsection{Cluster Analysis}

The evaluation of the current state of dairy cattle welfare (EV) was neutral on average (not poor and not good, mean $4.1 \pm 1.3$ on a scale of $1-7)$. EV was perceived as very negative-rather negative by $29 \%$ of respondents, as neutral by $31 \%$ and as rather good-very good by $40 \%$. With regard to the questions dealing with intention, mean intention to try was rather positive ( $3.9 \pm 0.8$ on a scale of $1-5)$ and intention to purchase from now on neutral-rather positive (3.6 \pm 0.9$)$. Most respondents (72\%) (strongly) stated to be willing to try animal-friendly milk, while only $4 \%$ (strongly) disagreed. For more than half of the respondents this resulted in a positive intention to purchase animal-friendly milk from now on (53\%). As IT and IP were highly correlated $(r=0.73, p<0.001)$, we will discuss them together under the term "intention to purchase" (IP) from here on.

The clustering procedure resulted in six clusters (Table 2, Figure 1). The existence of multiple consumer segments is in accordance with previous studies showing heterogeneity in interest in farm animal welfare $[11,12,32,33]$. We divided the clusters into three segments based on market opportunities. The first segment, with "high market opportunities", consists of cluster 2 (CL2) which is characterized by a high IP and a low EV. The second segment, referred to as "limited market opportunities", consists of three clusters (CL4, CL5 and CL6) and is characterized by a more positive perception of the current state of dairy cattle welfare and a neutral to low IP. The third segment, referred to as "moderate market opportunities", consists of two clusters (CL1 and CL3). Whereas CL1 does not seem concerned about dairy cattle welfare, they do have a positive IP, while CL3 does seem to be concerned about animal welfare (negative EV) with a neutral-rather positive IP. As some important nuances did exist between clusters in these three segments, further analysis was performed using all clusters, but results are mainly discussed using the three segments. However, where differences between clusters within segments are present, these will be discussed.

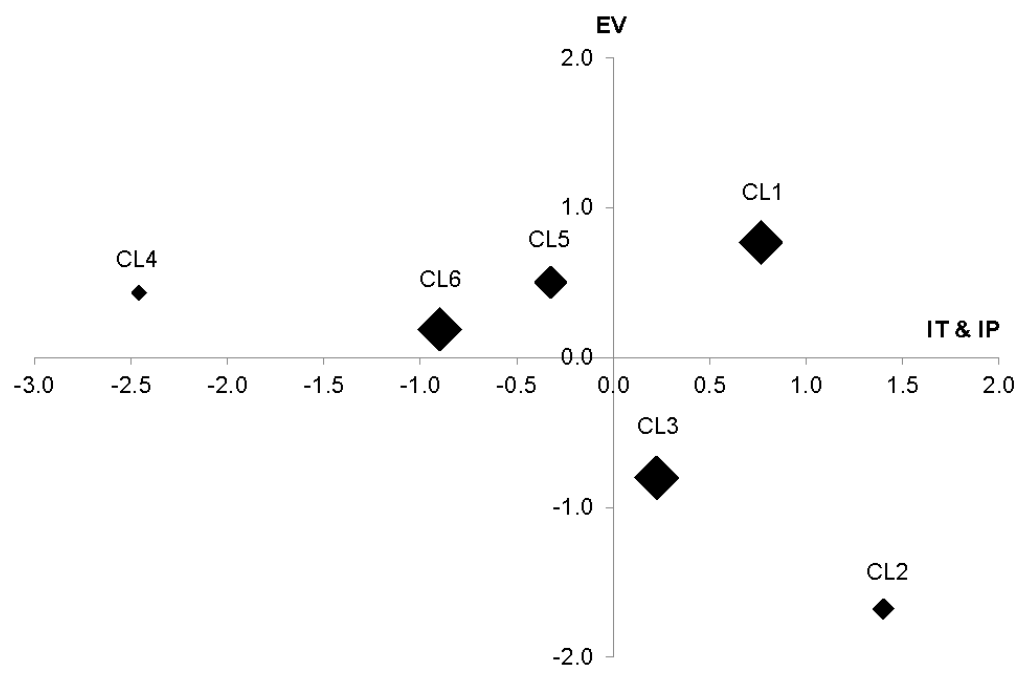

Figure 1. Mapping of the cluster centres (CL1-CL6) according to the evaluation of welfare (EV z-score) and intention to purchase welfare friendly milk (IT and IP z-score, mean of intention to try and intention to purchase from now on). The size of the marks reflects the relative size of the clusters (total $n=787$ ). 
Table 2. Segmentation variables, percentages of the sample and market opportunities for each cluster (CL) (Mean ( \pm Standard Deviation), $n=787)$.

\begin{tabular}{|c|c|c|c|c|c|c|}
\hline Cluster Code & CL1 & CL2 & CL3 & CL4 & CL5 & CL6 \\
\hline Market opportunities ${ }^{1}$ & Moderate & High & Moderate & Limited & Limited & Limited \\
\hline$\%$ of sample & 24.4 & 8.1 & 23.8 & 3.6 & 16.0 & 24.1 \\
\hline $\begin{array}{c}\text { Evaluation dairy cattle welfare } \\
\text { (EV, z-score) }\end{array}$ & 0.8 & -1.7 & -0.8 & 0.4 & 0.5 & 0.2 \\
\hline Evaluation dairy cattle welfare ${ }^{2}$ & $5.1 \pm 0.7$ & $1.8 \pm 0.8$ & $3.0 \pm 0.9$ & $4.6 \pm 1.3$ & $4.7 \pm 0.9$ & $4.3 \pm 0.9$ \\
\hline Intention to try (IT, z-score) & 0.7 & 1.3 & 0.2 & -2.7 & 0.2 & -1.1 \\
\hline Intention to try ${ }^{3}$ & $4.5 \pm 0.5$ & $5.0 \pm 0.0$ & $4.1 \pm 0.4$ & $1.6 \pm 0.6$ & $4.1 \pm 0.9$ & $3.0 \pm 0.9$ \\
\hline $\begin{array}{l}\text { Intention to purchase from now on } \\
\text { (IP, z-score) }\end{array}$ & 0.8 & 1.5 & 0.2 & -2.2 & -0.9 & -0.7 \\
\hline Intention to purchase from now on ${ }^{2}$ & $4.3 \pm 0.5$ & $4.9 \pm 0.3$ & $3.8 \pm 0.4$ & $1.7 \pm 0.5$ & $2.8 \pm 0.4$ & $3.0 \pm 0.3$ \\
\hline
\end{tabular}

\subsection{Socio-Demographics}

Fewer male respondents were found in the high market opportunities segment $(20 \%$ versus $49 \%-59 \%$ for moderate market opportunities and limited market opportunities, $p<0.001)$. This is in accordance with previous studies where females were more interested/concerned about animal welfare $[32,34,35]$. The high market opportunities segment also contained more respondents with a higher education $(54.7 \%)$, while there were fewer in the limited market opportunities segment (specifically, CL4: 32.1\%, CL6: 34.9\%, CL1: 45.8\%, CL3: 44.9\%, and CL5: 50.0\%, $p<0.001$ ). The profile of the high market opportunities segment corresponds to the "ethical consumers" that Vermeir and Verbeke [1] characterize as being more educated and better informed than average.

In CL4, more respondents indicated that they were familiar with livestock compared to the other clusters $(39.3 \%$ versus $15 \%-25 \%$ for the high market opportunities and moderate market opportunities segments, $p<0.001$ ). This is in line with a study by Boogaard et al. [36] among Dutch citizens who found that respondents with more stated familiarity with farming were more content with dairy farming practices. Vanhonacker et al. [32] found a similar cluster in their study and argued that the respondents were involved with animal production more on a socio-economical level than on a moral and ethical level.

As segments did not differ with respect to province, rural versus urban living conditions, familiarity with agriculture and age of the respondents, EV and IP appeared to be influenced by the respondents' attitudes, knowledge and opinions rather than by their socio-demographics. This is in accordance with earlier studies that question the usefulness of socio-demographic factors in studies involving ethical concerns [37-39].

\subsection{Market Opportunities}

\subsubsection{Milk Consumption}

Self-reported frequency of milk consumption did not differ between segments, which is in contrast with earlier studies concerning meat, where different clusters were found to indicate a different consumption pattern [38]. Regarding type of milk, respondents in the high market opportunities segment purchased significantly more organic milk compared to consumers of the other clusters $(p<0.001,10.9 \%$ for CL2 and $7.1 \%$ for CL4, versus $3.1 \%, 4.3 \%, 1.6 \%$ and $0.0 \%$ for CL1, CL3, CL5 and CL6, respectively). This is in line with expectations for this segment given their very positive intention to purchase animal-friendly milk.

\subsubsection{General Attitudes towards Milk and the Milk-Processing Industry}

Generally, the mean attitude towards milk score was positive $(4.0 \pm 0.8)$, and the attitude towards the milk-processing industry was neutral $(3.0 \pm 0.8)$. Both attitudes differed among clusters 
$(p<0.001)$. Attitude towards the milk-processing industry was more negative among the high market opportunities segment $(2.1 \pm 1.0)$ than for all other clusters. This is very likely related to their negative $\mathrm{EV}$, which reflects poorly on the milk-processing industry.

\subsubsection{Willingness to Pay}

The WTP differed for each price-increase category between clusters $(p<0.001$ for all). As measuring WTP using contingent valuation may be subject to hypothetical bias, we here use the results of this measure only to compare between segments, not to determine thresholds for maximum prices of animal-friendly milk. The pattern followed the IP indicated by the three segments. The high market opportunities segment indicated a higher WTP for all price-increases. Most clusters with limited market opportunities (CL4 and CL6) indicated a lower WTP for $0 \%$ increase, $5 \%$ and $10 \%$ (neutral and rather unlikely, respectively, Figure 2), and no majority indicated a positive WTP at any price level (i.e., maximum of $35 \%$ and $39 \%$ for a $0 \%$ price increase). The majority of respondents indicated a positive (likely or very likely) WTP up to a price increase of $20 \%$ for CL2, 10\% for CL1 and CL3 and 5\% for CL5.

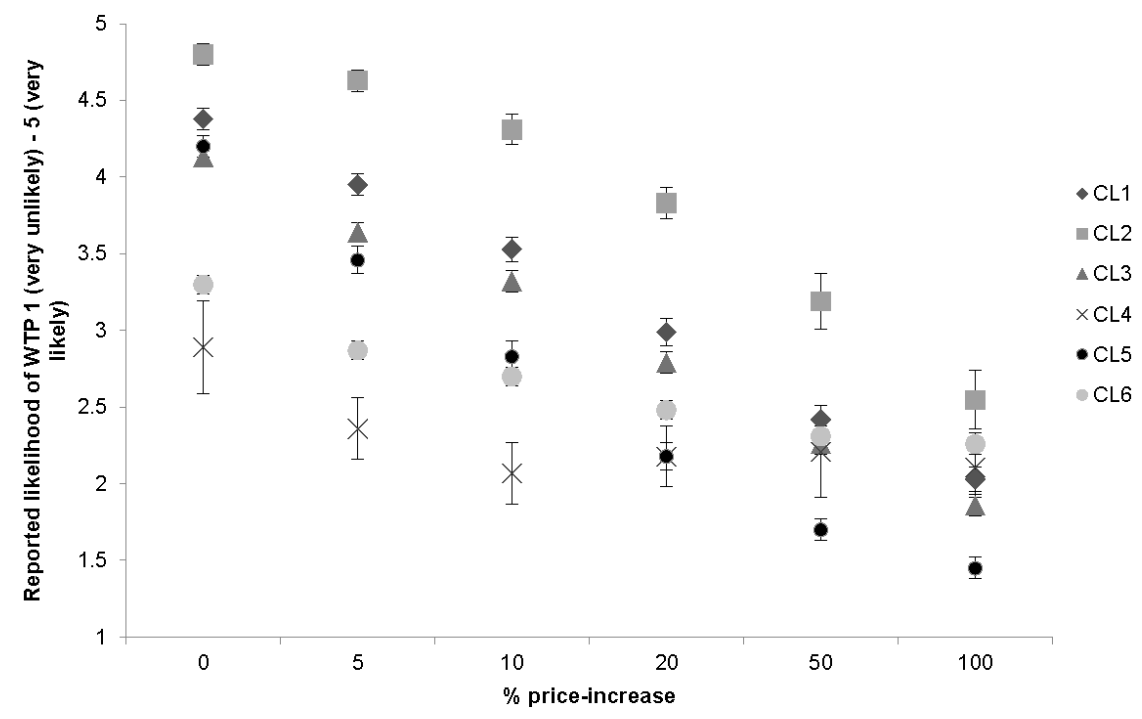

Figure 2. Mean willingness-to-pay scores \pm SEM for CL1-CL6, per \% of price-increase.

\subsubsection{Considerations-Market Opportunities}

The most pronounced differences between segments were found for the WTP, where the segment that indicated a higher IT and IP (high market opportunities) also showed a higher WTP. This segment would likely purchase products with the highest level of animal welfare, with a matching price (currently organic milk in the Flemish market). Attitudes towards milk as a product were positive, with generally neutral attitudes towards the dairy industry. Along with the finding that milk consumption frequency did not differ between clusters, these findings indicate the existence of market opportunities for animal-friendly milk, both for the highest level of animal welfare and for more intermediate products.

\subsection{Communication about Animal-Friendly Milk}

\subsubsection{Perceived Importance of Product Attributes}

The perceived importance of all milk attributes differed among clusters $(p<0.001$, Table 3$)$, in a somewhat different pattern than the segments. Generally, CL1 and CL2 indicated the highest importance for most attributes (all rather important to very important), CL3 and CL5 mostly indicated "neutral"-"rather interested" and the CL4 and CL6 most often indicated "neutral". An exception was 
the attribute "price", which CL1 and CL5 scored highest (both "very important"). These findings indicate that although CL1 might be a more conscious consumer than CL3, they do value price a lot, which causes lower market opportunities than for CL2.

The absolute importance scores for the product attribute "animal welfare" ranged from "neutral" for CL4 and CL6, to "rather important" for CL3 and CL5 clusters and "very important" for CL1 and CL2. However, when viewing the product attribute "animal welfare" relative to other product attributes, the high market opportunities and moderate market opportunities segments scored animal welfare among the more important product attributes, and the limited market opportunities segment among the less important product attributes (paired samples t-test, $p<0.001$ ).

Table 3. Perceived importance of product attributes (Mean \pm Standard Deviation, $n=787$ ).

\begin{tabular}{|c|c|c|c|c|c|c|c|c|}
\hline & Sample & CL1 & CL2 & CL3 & CL4 & CL5 & CL6 & $p$-Value \\
\hline Packaging & $3.2 \pm 1.0$ & $3.5 \pm 1.0^{b}$ & $3.2 \pm 1.3^{\mathrm{a}, \mathrm{b}}$ & $3.2 \pm 1.0^{\mathrm{a}, \mathrm{b}}$ & $3.1 \pm 1.1^{\mathrm{a}}$ & $3.1 \pm 1.0^{\mathrm{a}}$ & $3.1 \pm 0.8^{\mathrm{a}}$ & $<0.001$ \\
\hline Country of origin & $3.5 \pm 1.0$ & $3.9 \pm 0.9^{b}$ & $4.0 \pm 1.1^{\mathrm{b}}$ & $3.4 \pm 1.0^{\mathrm{a}}$ & $3.0 \pm 1.1^{\mathrm{a}}$ & $3.3 \pm 1.0^{\mathrm{a}}$ & $3.2 \pm 0.8^{\mathrm{a}}$ & $<0.001$ \\
\hline Fair trade & $3.5 \pm 1.0$ & $3.9 \pm 0.9^{c}$ & $4.2 \pm 1.1^{\mathrm{c}}$ & $3.6 \pm 0.8^{b}$ & $3.0 \pm 1.2^{\mathrm{a}, \mathrm{b}}$ & $3.2 \pm 1.0^{\mathrm{a}}$ & $3.2 \pm 0.7^{\mathrm{a}}$ & $<0.001$ \\
\hline Local production & $3.6 \pm 0.9$ & $4.0 \pm 0.8^{b}$ & $4.1 \pm 1.0^{\mathrm{b}}$ & $3.5 \pm 0.9^{a}$ & $3.0 \pm 1.1^{\mathrm{a}}$ & $3.3 \pm 1.0^{\mathrm{a}}$ & $3.2 \pm 0.7^{\mathrm{a}}$ & $<0.001$ \\
\hline $\begin{array}{l}\text { Method of } \\
\text { production }\end{array}$ & $3.7 \pm 0.9$ & $4.0 \pm 0.7^{c}$ & $4.6 \pm 0.6^{\mathrm{d}}$ & $3.8 \pm 0.8^{b}$ & $3.0 \pm 1.0^{\mathrm{a}}$ & $3.4 \pm 0.9^{\mathrm{a}}$ & $3.3 \pm 0.7^{\mathrm{a}}$ & $<0.001$ \\
\hline Sustainability & $3.8 \pm 0.8$ & $4.1 \pm 0.7^{\mathrm{d}}$ & $4.3 \pm 0.7^{\mathrm{d}}$ & $3.8 \pm 0.7^{\mathrm{c}}$ & $3.1 \pm 1.1^{\mathrm{a}, \mathrm{b}}$ & $3.6 \pm 0.9^{b, c}$ & $3.4 \pm 0.7^{\mathrm{a}}$ & $<0.001$ \\
\hline $\begin{array}{l}\text { Environmental } \\
\text { friendliness }\end{array}$ & $3.8 \pm 0.8$ & $4.1 \pm 0.7^{c}$ & $4.5 \pm 0.8^{\mathrm{d}}$ & $3.9 \pm 0.6^{b}$ & $3.1 \pm 0.9^{\mathrm{a}}$ & $3.5 \pm 0.9^{\mathrm{a}}$ & $3.3 \pm 0.7^{\mathrm{a}}$ & $<0.001$ \\
\hline Price & $3.9 \pm 0.8$ & $4.1 \pm 0.8^{b, c}$ & $3.7 \pm 1.0^{\mathrm{a}, \mathrm{b}}$ & $3.9 \pm 0.8^{b}$ & $3.8 \pm 1.1^{\mathrm{a}, \mathrm{b}, \mathrm{c}}$ & $4.2 \pm 0.7^{c}$ & $3.6 \pm 0.8^{a}$ & $<0.001$ \\
\hline Animal welfare & $4.0 \pm 0.9$ & $4.3 \pm 0.7^{c}$ & $4.9 \pm 0.3^{\mathrm{d}}$ & $4.2 \pm 0.6^{c}$ & $3.3 \pm 1.0^{\mathrm{a}, \mathrm{b}}$ & $3.7 \pm 0.8^{b}$ & $3.4 \pm 0.8^{a}$ & $<0.001$ \\
\hline Taste & $4.1 \pm 0.7$ & $4.4 \pm 0.6^{c}$ & $4.6 \pm 0.5^{\mathrm{d}}$ & $4.1 \pm 0.6^{b}$ & $3.5 \pm 0.7^{\mathrm{a}}$ & $4.1 \pm 0.6^{b}$ & $3.6 \pm 0.8^{a}$ & $<0.001$ \\
\hline Health & $4.1 \pm 0.8$ & $4.4 \pm 0.6^{\mathrm{d}}$ & $4.8 \pm 0.4^{\mathrm{e}}$ & $4.2 \pm 0.7^{c}$ & $3.5 \pm 0.9^{a, b, c}$ & $4.0 \pm 0.7^{b}$ & $3.6 \pm 0.8^{a}$ & $<0.001$ \\
\hline Quality & $4.1 \pm 0.7$ & $4.5 \pm 0.6^{c}$ & $4.7 \pm 0.5^{c}$ & $4.2 \pm 0.6^{\mathrm{a}, \mathrm{b}}$ & $3.6 \pm 1.1^{\mathrm{a}}$ & $4.2 \pm 0.6^{b}$ & $3.6 \pm 0.8^{\mathrm{a}}$ & $<0.001$ \\
\hline Food safety & $4.2 \pm 0.8$ & $4.5 \pm 0.6^{c}$ & $4.8 \pm 0.4^{\mathrm{d}}$ & $4.2 \pm 0.6^{\mathrm{b}}$ & $3.5 \pm 1.1^{\mathrm{a}}$ & $4.3 \pm 0.7^{b}$ & $3.6 \pm 0.8^{a}$ & $<0.001$ \\
\hline Freshness & $4.2 \pm 0.7$ & $4.5 \pm 0.6^{c}$ & $4.7 \pm 0.7^{c}$ & $4.2 \pm 0.6^{b}$ & $3.9 \pm 0.8^{\mathrm{a}, \mathrm{b}}$ & $4.3 \pm 0.7^{b, c}$ & $3.7 \pm 0.8^{\mathrm{a}}$ & $<0.001$ \\
\hline
\end{tabular}

\subsubsection{Information Sources and Preferred Format of Information on Dairy Cattle Welfare}

All clusters indicated a neutral to rather negative score for "the dairy processing industry" regarding trust as a source of animal welfare information (Table 4). Possibly, this is caused by the industries vested interests in milk, which potentially biases towards creating a positive image. Besides a negative score for "the dairy processing industry", the high market opportunities segment indicated rather negative scores for trust in "government", "supermarket", and "farmer" as well. This is likely related to their low EV-score, which reflects poorly on these stakeholders. The most trusted sources of an animal-friendly milk label were veterinarians and animal welfare organizations, as all clusters indicated a neutral to positive trust in these segments.

Content of the label for all categories (i.e., "general cow welfare", "focus on access to pasture", "focus on specific welfare problems", "sustainability" and "local production") was least preferred by CL4 and CL6 (scored neutral to rather uninteresting, Table 3). The high market opportunities segment showed the highest preference for all suggested label content (scored rather to very interesting). The same goes for the type of label. None of the segments indicated a clear preference for any of the label contents.

Regarding the type of dairy cattle welfare label, preference was given to a label with a star rating system by the high market opportunities and moderate market opportunities segments. The limited segments' scores did not differ significantly between the options. These results are in line with the "extremeness aversion" theory [40], meaning that when a wider range of products is provided, consumers are less likely to choose the cheapest product. In animal welfare products, a similar construct has been examined studies [14,15], who found a smaller share of respondents choosing for 
the product lowest in price and animal welfare when products at intermediate levels of animal welfare and price were offered. An example of a similar and rather successful labelling scheme (representing approximately $22 \%$ of the egg market share) can be found in The Netherlands, where an animal welfare organization (Dierenbescherming) developed a label with star rating system to indicate different levels of animal welfare for various farm animal species. In addition, the recently established state-controlled animal welfare label in Denmark (Bedre Dyrevelfærd) that will enter the market in 2017 distinguishes between three levels of improved welfare following similar principles, though using hearts instead of stars.

Table 4. Preferred source, content of a label and type of label (Mean \pm Standard Deviation, $n=787$, between-segments $p$-value $<0.001$ for all).

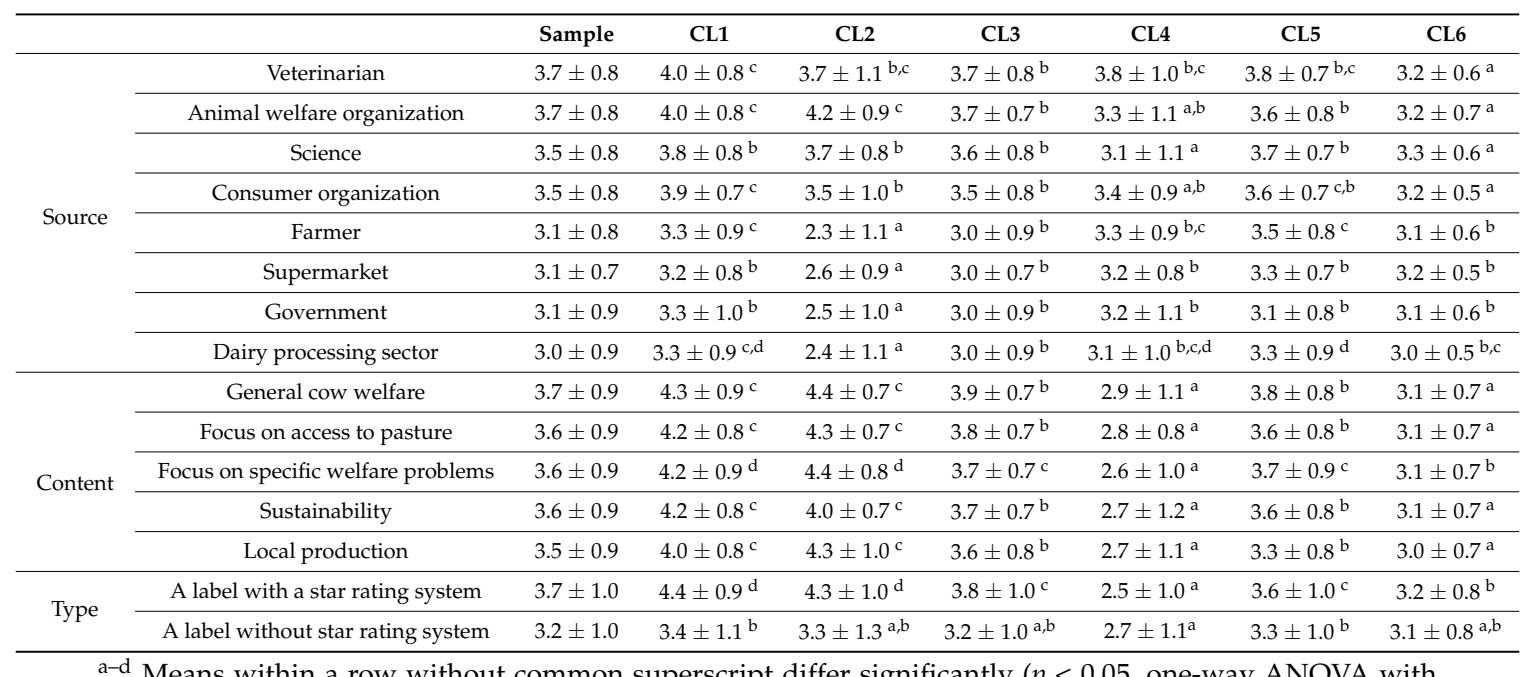

${ }^{a-d}$ Means within a row without common superscript differ significantly $(p<0.05$, one-way ANOVA with

Dunnett's T3 post hoc comparison of mean scores).

\subsubsection{Interest in Information about WQ Measures and Criteria}

Two findings were most apparent from the respondents' interest in information about WQ measures and criteria. First, for all measures and criteria, interest in information between clusters differed significantly $(p<0.001$ for all; interest scores for all measures and criteria can be found in the Appendix). Post-hoc tests showed a clear pattern: interest in information in measures and criteria was lowest for the "limited market opportunities" segment (mean scores ranged from 27.1-35.9 for CL4, 27.9-58.6 for CL5, and 32.8-45.2 for CL6), followed by the "moderate" segment (CL1: 44.3-78.4 and CL3: 43.9-72.9) and highest for the segment with "high market opportunities" (CL2: 66.1-93.6) ( $p<0.05$ for all differences). Second, even though interest in all measures differed, generally the same criteria and measures received the highest importance score for all clusters. This is not in accordance with previous studies where heterogeneity in perceived important factors for farm animal welfare was found (e.g., for broiler chickens [11]). However, in these studies respondents were not given a list of (WQ) welfare impairments, but were asked to think of them themselves. When a predetermined list was given to respondents, (as done by Tuyttens et al. [41] using WQ criteria), the same criteria were found among the most and least important scores.

Both the high and moderate segments indicated most interest in "freedom of movement", whereas the limited opportunities segment attached most interest to "absence of diseases" (all $p$-values $<0.05$ ). The moderate market opportunities segment and CL5 indicated the second-to most interest in absence of diseases, although moderate clusters indicated as much interest for "absence of injuries" (CL5), "comfort around resting" (CL3), "good human-animal relationship" (CL3) and "positive emotional state" (CL3). The high market opportunities and moderate market opportunities segments, and CL6, generally indicated least interest for the criteria "expression of other normal behaviour" and "expression of social behaviour". Both CL4 and CL5 did not score any of the criteria as lower than most 
other criteria. Regarding measures, highest scores (all $p<0.05$ ) by the moderate market opportunities segment and CL5 and CL6 were attributed to "access to pasture", but some scored "expression of positive behaviour" (CL1, CL3, CL5, and CL6), "expression of negative behaviour" (CL1, CL3, CL5, and CL6), dehorning method (CL3), tail docking method, "number of drinking points, cleanliness and functioning of the drinking points" (CL3) and "tied housing" (CL3, CL5, and CL6) equally high. CL2 scored all the aforementioned measures equally high, and CL4 scored all equally low.

While most segments attributed lowest scores to the criterion measured using "access to pasture" (criterion "expression of normal behaviour"), this measure was given the highest importance score by the majority of segments. Possibly, freedom of movement was associated with access to pasture by the respondents (which actually is a measure of the criterion "expression of normal behaviour") which explains this discrepancy. Access to pasture is consistently mentioned in literature as being highly important to citizens [8,42,43]. Additionally, although the criterion "absence of diseases" was scored high by many clusters, none of the measures for diseases were among the highest scores for most clusters. It is likely that a high level of knowledge or familiarity is needed to understand the importance of these specific welfare measures, while a general lack of knowledge about farming practices and specific welfare problems among consumers has been shown [44]. Besides a lack of knowledge, respondents also seemed to not prefer specific information, given that the least preferred content for an animal-friendly label was "specific welfare problems". The latter is in accordance with previous studies which found that too detailed information (or information overload) could have a detrimental effect on the intention to purchase $[33,45,46]$.

\subsubsection{Considerations-Communication Targeted to the Various Segments}

Generally, animal welfare was scored as a neutral to a very important product attribute, but less important than taste, health, quality, food safety and freshness. This is in accordance with earlier studies, which report that consumers generally give higher priority to primary product attributes like quality, health and safety than to aspects related to moral issues and/or sustainability such as fair trade, local production and animal welfare $[14,47,48]$. By underlining the product attributes that are considered most important in milk, consumers who are negative or neutral in their intention to purchase might see benefits of the animal-friendly products. Perceived benefits from animal-friendly milk (e.g., healthier and better quality) have previously been found to be related to intention to purchase previously [49] and could change consumers' purchase behaviour. Naturally, these benefits would have to actually exist in order to make such claims about animal-friendly milk. A study has already shown a positive relationship between milk quality and animal welfare [50], but more research on this subject is still needed.

The most trusted sources for information on cow welfare were veterinarians and animal welfare organizations. Regarding type of dairy cattle welfare label, general preference was given to a label with a star rating. Regarding interest in information about the current state of animal welfare, the measure "access to pasture" and criterion "freedom of movement" were considered to be most interesting. Although the WQ criterion "absence of diseases" was among the highest scores as well, using individual diseases or injuries like lameness or mastitis as attributes to communicate does not seem a promising route, because no preference was given to this type of welfare label, nor to the WQ measures of disease.

\section{Conclusions}

The objective of this paper was to explore market opportunities for sustainable products, specifically animal-friendly milk, by identifying and profiling market segments based on a consumerand a citizen-oriented segmentation variable (IP and EV, respectively). A high degree of differentiation within the Flemish market for milk was shown (six consumer clusters), with identification of market opportunities for animal-friendly milk, while the market supply does not show a similar differentiation. Intention to purchase and, to a lesser degree, WTP were strongly linked to interest in information about 
animal welfare. The consumer segment with the highest IP and WTP is believed to be most interested in the products with the highest level of animal welfare (e.g., organic and high market opportunities segment). In addition, this segment was most negative regarding the state of animal welfare and the dairy industry. Milk with the highest level of both price and animal welfare could be positioned in the market by primarily focusing on enhanced welfare as this appears to be a dominant selection criterion for the segment with high market opportunities. This study lays the foundation for future research, which could focus on examining consumer segments with moderate and/or limited market opportunities, where communication could highlight specific benefits (e.g., healthier and better quality) at an intermediate level of animal welfare and price to change these consumers' purchase behaviour.

Although, in this paper, we collated clusters based on market opportunities to form three segments, some crucial differences between clusters within segments were apparent. While CL5 was identified as having "limited" market opportunities, this cluster did seem somewhat more interested in animal-friendly milk than CL4 and CL6 within the same segment. Since age was not associated with the clusters, a transition of individuals from one segment to another, e.g., from limited to moderate, or from moderate to high, is unlikely to happen automatically over time as the simple result of people's ageing. Specific efforts that aim at stimulating such a transition will be needed, and the fact that gender is associated with clusters indicates that extra efforts targeting male consumers might be required. The use of informational approaches emerges as a potential strategy. The finding that education is associated with clusters suggests that better and more easily accessible information may be effective in moving people from one to another segment. Such informational approaches could focus on the state of animal welfare or on the precise characteristics of animal-friendly products.

Promising selling propositions in future communication about animal-friendly milk were found to be "access to pasture" and the related criterion (according to respondents) "freedom of movement", and the criterion "absence of diseases". Our results reveal an information need that confirms actual practices as foreseen in operational labelling systems, such as a star rating system differentiating between diverse levels of animal welfare at different price levels. Marketing effort that underlines access to pasture and the healthiness of cows would play into the publics' interests regarding dairy cattle welfare. To position products with the highest level of price and animal welfare, enhanced welfare could be the main focus, whereas intermediate products could be positioned based on benefits of increased cow welfare for milk. When the market supply would be better aligned with the heterogeneous demand, for instance by using a star (or equivalent) rating system, the market share of animal-friendly products could increase. Additionally, such a rating system could encourage farmers to invest in improved cow welfare as a higher rating could translate into a higher price for their dairy products.

The results obtained in the present study are specific for milk in Flanders, Belgium. Nevertheless, it is likely that the finding of a high degree of differentiation in the market based on consumers' intention to purchase and their evaluation of the state of animal welfare as an attribute of livestock products, as well as the existence of related market opportunities, can be extrapolated to other livestock products, animal species, and regions. Further research into this domain is recommended.

Acknowledgments: The authors thank Miriam Levenson for language editing. We also thank the ILVO personnel of Social Sciences and Animal Sciences for pre-testing the questionnaire.

Author Contributions: Sophie de Graaf, Filiep Vanhonacker, Jo Bijttebier, Ludwig Lauwers, Frank A. M. Tuyttens and Wim Verbeke conceived and designed the study; Sophie de Graaf analysed the data; Sophie de Graaf wrote the paper; and Filiep Vanhonacker, Jo Bijttebier, Ludwig Lauwers, Ellen Van Loo, Frank A. M. Tuyttens and Wim Verbeke provided necessary feedback during the research process, and proofread the paper.

Conflicts of Interest: The authors declare no conflict of interest. 


\section{Appendix A}

Table A1. Mean scores of the interest in information about WQ measures and criteria for the entire sample $(p<0.001$ for all $)$ and per cluster.

\begin{tabular}{|c|c|c|c|c|c|c|c|}
\hline WQ Criteria and WQ Measures & Sample & CL1 & CL2 & CL3 & CL4 & CL5 & CL6 \\
\hline Absence of prolonged hunger & 57.58 & $68.70^{c}$ & $91.73^{d}$ & $63.83^{c}$ & $27.21^{\mathrm{a}}$ & $46.02^{b}$ & $40.74^{\mathrm{a}, \mathrm{b}}$ \\
\hline The number of cows on a farm that are too thin & 50.95 & $59.71^{b}$ & $84.23^{c}$ & $57.50^{\mathrm{b}}$ & $25.64^{\mathrm{a}}$ & $36.38^{\mathrm{a}}$ & $37.74^{\mathrm{a}}$ \\
\hline Absence of prolonged thirst & 57.80 & $68.82^{b}$ & $90.23^{c}$ & $64.89^{\mathrm{b}}$ & $29.82^{a}$ & $46.33^{a}$ & $40.40^{\mathrm{a}}$ \\
\hline Number of drinking points, cleanliness and functioning of the drinking points & 56.40 & $66.51^{\mathrm{b}}$ & $89.41^{\mathrm{c}}$ & $62.68^{\mathrm{b}}$ & $27.64^{\mathrm{a}}$ & $44.84^{\mathrm{a}}$ & $40.69^{\mathrm{a}}$ \\
\hline Comfort around resting & 58.56 & $70.19^{c}$ & $90.53^{d}$ & $66.10^{c}$ & $25.82^{\mathrm{a}}$ & $45.94^{b}$ & $41.66^{\mathrm{b}}$ \\
\hline Number of cows on a farm colliding with housing equipment when they lie down & 43.22 & $46.96^{\mathrm{b}}$ & $79.53^{c}$ & $48.57^{b}$ & $23.64^{\text {a }}$ & $31.17^{\mathrm{a}}$ & $32.77^{a}$ \\
\hline $\begin{array}{l}\text { The number of cows on a farm that lie down on places that are not meant for lying } \\
\text { (indication of a dirty or unsuitable lying area) }\end{array}$ & 50.90 & $58.76^{\mathrm{b}}$ & $88.28^{\mathrm{c}}$ & $56.43^{\mathrm{b}}$ & $25.14^{\mathrm{a}}$ & $38.44^{\mathrm{a}}$ & $36.90^{\mathrm{a}}$ \\
\hline The number of cows on the farm with dirty legs, udder or flanks & 48.32 & $54.91^{\mathrm{b}}$ & $78.61^{\mathrm{c}}$ & $55.13^{\mathrm{b}}$ & $23.64^{\mathrm{a}}$ & $34.03^{\mathrm{a}}$ & $37.83^{\mathrm{a}}$ \\
\hline $\begin{array}{l}\text { The time that it takes for a cow to lie down as indicator of pain or fear of colliding with } \\
\text { housing equipment }\end{array}$ & 47.77 & $54.11^{\mathrm{b}}$ & $83.59^{c}$ & $53.41^{b}$ & $27.61^{\mathrm{a}}$ & $33.85^{\mathrm{a}}$ & $35.87^{\mathrm{a}}$ \\
\hline Freedom of movement & 65.22 & $78.43^{c}$ & $93.44^{\mathrm{d}}$ & $72.89^{c}$ & $33.25^{\mathrm{a}}$ & $58.62^{b}$ & $43.78^{\mathrm{a}}$ \\
\hline Housing where the cows are tied instead of able to walk around freely & 57.93 & $67.11^{\mathrm{b}}$ & $92.23^{\mathrm{c}}$ & $64.72^{b}$ & $32.32^{\mathrm{a}}$ & $47.31^{\mathrm{a}}$ & $41.13^{\mathrm{a}}$ \\
\hline Absence of injuries & 57.88 & $68.27^{c}$ & $86.97^{\mathrm{d}}$ & $64.89^{c}$ & $27.43^{\mathrm{a}}$ & $47.25^{b}$ & $42.29^{\mathrm{a}, \mathrm{b}}$ \\
\hline The number of lame cows on the farm & 53.11 & $60.05^{b}$ & $88.67^{c}$ & $59.37^{\mathrm{b}}$ & $32.43^{\mathrm{a}}$ & $39.90^{\mathrm{a}}$ & $39.69^{\mathrm{a}}$ \\
\hline The number of cows on a farm with hairless patches. cuts and/or swellings & 54.23 & $62.09^{b}$ & $88.59^{c}$ & $61.14^{\mathrm{b}}$ & $32.71^{\mathrm{a}}$ & $41.59^{\mathrm{a}}$ & $39.37^{\mathrm{a}}$ \\
\hline Absence of diseases & 63.00 & $73.99^{c}$ & $89.36^{\mathrm{d}}$ & $68.64^{c}$ & $35.93^{\mathrm{a}, \mathrm{b}}$ & $57.17^{\mathrm{b}}$ & $45.24^{\mathrm{a}}$ \\
\hline The number of cows on a farm that cough and sneeze & 51.99 & $59.80^{\mathrm{b}}$ & $84.69^{\mathrm{c}}$ & $57.58^{\mathrm{b}}$ & $29.50^{\mathrm{a}}$ & $41.96^{\mathrm{a}}$ & $37.49^{\mathrm{a}}$ \\
\hline The number of cows on a farm with a runny nose or runny eye (symptom of an infection) & 53.97 & $62.85^{\mathrm{b}}$ & $87.50^{\mathrm{c}}$ & $58.08^{\mathrm{b}}$ & $33.39^{a}$ & $42.35^{\mathrm{a}}$ & $40.33^{\mathrm{a}}$ \\
\hline The number of cows on a farm that have difficulty breathing & 54.19 & $62.10^{\mathrm{b}}$ & $88.86^{\mathrm{c}}$ & $59.70^{\mathrm{b}}$ & $32.00^{\mathrm{a}}$ & $44.22^{\mathrm{a}}$ & $38.90^{\mathrm{a}}$ \\
\hline The number of cows on a farm with diarrhoea & 54.24 & $61.46^{\mathrm{b}}$ & $87.77^{\mathrm{c}}$ & $59.23^{b}$ & $33.86^{\mathrm{a}}$ & $42.34^{\mathrm{a}}$ & $41.56^{\mathrm{a}}$ \\
\hline The number of cows on a farm with a vaginal or uterine infection & 53.39 & $62.75^{b}$ & $88.83^{c}$ & $57.81^{\mathrm{b}}$ & $27.54^{\mathrm{a}}$ & $40.94^{\mathrm{a}}$ & $39.63^{a}$ \\
\hline The number of cows on a farm with an udder infection & 57.77 & $66.86^{\mathrm{b}}$ & $89.33^{c}$ & $63.07^{\mathrm{b}}$ & $34.71^{\mathrm{a}}$ & $48.05^{\mathrm{a}}$ & $42.52^{\mathrm{a}}$ \\
\hline The number of cows on a farm that have died & 50.98 & $59.22^{b}$ & $84.67^{\mathrm{c}}$ & $54.64^{\mathrm{b}}$ & $31.46^{\mathrm{a}}$ & $40.75^{\mathrm{a}}$ & $37.29^{\mathrm{a}}$ \\
\hline The number of difficult calvings & 39.86 & $44.32^{b}$ & $66.08^{\mathrm{c}}$ & $43.88^{\mathrm{b}}$ & $24.32^{\mathrm{a}}$ & $27.86^{\mathrm{a}}$ & $32.78^{\mathrm{a}}$ \\
\hline The number of cows on a farm that could not stand upright anymore & 52.09 & $60.35^{b}$ & $87.31^{c}$ & $57.93^{\mathrm{b}}$ & $25.43^{\mathrm{a}}$ & $41.45^{\mathrm{a}}$ & $37.02^{\mathrm{a}}$ \\
\hline
\end{tabular}


Table A1. Cont.

\begin{tabular}{|c|c|c|c|c|c|c|c|}
\hline WQ Criteria and WQ Measures & Sample & CL1 & CL2 & CL3 & CL4 & CL5 & CL6 \\
\hline Absence of pain induced by management procedures & 56.99 & $67.53^{c}$ & $89.50^{\mathrm{d}}$ & $63.98^{c}$ & $27.11^{\mathrm{a}}$ & $45.64^{b}$ & $40.35^{\mathrm{a}, \mathrm{b}}$ \\
\hline $\begin{array}{l}\text { The number of cows on a farm where the horns are removed using a caustic paste in } \\
\text { comparison to a soldering iron and whether anaesthesia or pain medication is used } \\
\text { during this procedure }\end{array}$ & 54.17 & $61.44^{\mathrm{b}}$ & $90.81^{c}$ & $62.05^{b}$ & $28.07^{a}$ & $43.25^{\mathrm{a}}$ & $37.72^{\mathrm{a}}$ \\
\hline $\begin{array}{l}\text { The number of cows on a farm whose tail has been removed using a rubber band instead } \\
\text { of an operation and whether anaesthesia or pain medication was used during } \\
\text { this procedure }\end{array}$ & 54.18 & $61.55^{\mathrm{b}}$ & $90.30^{c}$ & $61.23^{\mathrm{b}}$ & $26.71^{a}$ & $43.16^{\mathrm{a}}$ & $38.92^{\mathrm{a}}$ \\
\hline Expression of social behaviour & 55.44 & $64.72^{b}$ & $83.75^{c}$ & $63.04^{\mathrm{b}}$ & $32.68^{a}$ & $45.98^{a}$ & $38.58^{a}$ \\
\hline Cows butting heads or showing other aggressive behaviour among themselves & 43.77 & $48.79^{\mathrm{b}}$ & $76.56^{\mathrm{c}}$ & $49.34^{b}$ & $27.21^{\mathrm{a}}$ & $29.75^{a}$ & $33.86^{\mathrm{a}}$ \\
\hline Expression of other normal behaviour & 55.03 & $65.39^{c}$ & $84.89^{\mathrm{d}}$ & $62.11^{c}$ & $25.18^{a}$ & $45.00^{\mathrm{b}}$ & $38.51^{\mathrm{a}, \mathrm{b}}$ \\
\hline $\begin{array}{l}\text { The number of days per year that the cows have access to a pasture for more than } \\
6 \mathrm{~h} \text { per day }\end{array}$ & 60.31 & $72.18^{c}$ & $89.27^{\mathrm{d}}$ & $65.78^{c}$ & $29.46^{\mathrm{a}}$ & $51.79^{\mathrm{b}}$ & $43.30^{\mathrm{a}, \mathrm{b}}$ \\
\hline Good human-animal relationship & 60.60 & $71.86^{\mathrm{b}}$ & $91.17^{c}$ & $68.64^{\mathrm{b}}$ & $33.14^{\mathrm{a}}$ & $48.37^{\mathrm{a}}$ & $43.07^{\mathrm{a}}$ \\
\hline Number of cows that are not approachable by people (indicates cows' fear of people) & 50.25 & $57.84^{\mathrm{b}}$ & $83.66^{\mathrm{a}}$ & $56.71^{\mathrm{b}}$ & $25.75^{a}$ & $37.76^{\mathrm{a}}$ & $36.78^{a}$ \\
\hline Positive emotional state & 57.34 & $68.18^{b}$ & $89.25^{c}$ & $66.39^{b}$ & $26.57^{a}$ & $44.67^{\mathrm{a}}$ & $39.57^{a}$ \\
\hline $\begin{array}{l}\text { Showing positive behaviour (active, relaxed, calm, content, friendly, playful, positively } \\
\text { occupied, lively, curious, social and happy) }\end{array}$ & 60.10 & $72.82^{b}$ & $92.45^{c}$ & $67.50^{\mathrm{b}}$ & $30.32^{a}$ & $48.45^{\mathrm{a}}$ & $41.08^{a}$ \\
\hline $\begin{array}{l}\text { Showing negative behaviour (fearful, irritated, indifferent, frustrated, bored, agitated, } \\
\text { nervous, apathetic and stressed) }\end{array}$ & 60.92 & $72.48^{\mathrm{b}}$ & $93.59^{c}$ & $68.48^{\mathrm{b}}$ & $35.71^{a}$ & $49.41^{\mathrm{a}}$ & $42.03^{a}$ \\
\hline
\end{tabular}

${ }^{a-d}$ Means within a row without common superscript differ significantly $(p<0.05$, one-way ANOVA with Dunnett's T3 post hoc comparison of mean scores). 


\section{References}

1. Vermeir, I.; Verbeke, W. Sustainable food consumption: Exploring the consumer attitude-behavioral intention. J. Agric. Environ. Ethics 2006, 19, 169-194. [CrossRef]

2. Briggeman, B.C.; Lusk, J.L. Preferences for fairness and equity in the food system. Eur. Rev. Agric. Econ. 2010. [CrossRef]

3. European Commission. Attitudes of Europeans towards Animal Welfare; Special Eurobarometer 442; European Commission: Brussels, Belgium, 2016.

4. Harper, G.C.; Makatouni, A. Consumer perception of organic food production and farm animal welfare. Br. Food J. 2002, 104, 287-299. [CrossRef]

5. Van Loo, E.J.; Caputo, V.; Nayga, R.M.; Meullenet, J.-F.; Crandall, P.G.; Ricke, S.C. Effect of organic poultry purchase frequency on consumer attitudes toward organic poultry meat. J. Food Sci. 2010, 75, S384-S397. [CrossRef] [PubMed]

6. Van Loo, E.J.; Caputo, V.; Nayga, R.M.; Verbeke, W. Consumers' valuation of sustainability labels on meat. Food Policy 2014, 49, 137-150. [CrossRef]

7. Samborski, V.; Van Bellegem, L. De Biologische Landbouw in Vlaanderen: Stand van Zaken 2014; Departement Landbouw en Visserij: Brussels, Belgium, 2014; p. 15.

8. Harvey, D.; Hubbard, C. Reconsidering the political economy of farm animal welfare: An anatomy of market failure. Food Policy 2013, 38, 105-114. [CrossRef]

9. Toma, L.; McVittie, A.; Hubbard, C.; Stott, A.W. A structural equation model of the factors influencing British consumers' behaviour toward animal welfare. J. Food Prod. Mark. 2011, 17, 261-278. [CrossRef]

10. Dagevos, H.; Sterrenberg, L. Burgers en Consumenten: Tussen Tweedeling en Twee-Eenheid; Wageningen Academic Publishers: Wageningen, The Netherlands, 2003.

11. Hall, C.; Sandilands, V. Public attitudes to the welfare of broiler chickens. Anim. Welf. 2007, 16, 499-512.

12. Liljenstolpe, C. Evaluating animal welfare with choice experiments: An application to Swedish pig production. Agribusiness 2008, 24, 67-84. [CrossRef]

13. Vanhonacker, F.; Van Poucke, E.; Tuyttens, F.; Verbeke, W. Citizens' views on farm animal welfare and related information provision: Exploratory insights from Flanders, Belgium. J. Agric. Environ. Ethics 2010, 23, 551-569. [CrossRef]

14. De Jonge, J.; van der Lans, I.A.; van Trijp, H.C. Different shades of grey: Compromise products to encourage animal friendly consumption. Food Qual. Preference 2015, 45, 87-99. [CrossRef]

15. Van Herpen, E.; Fischer, A.R.; van Trijp, H.C. How to position 'mildly sustainable' products: The joint impact of assortment display and price setting. Food Qual. Preference 2015, 46, 26-32. [CrossRef]

16. Weinrich, R.; Spiller, A. Developing food labeling strategies: Multi-level labeling. J. Clean. Prod. 2016, 137, 1138-1148. [CrossRef]

17. Eurobarometer, S. Attitudes of EU Citizens towards Animal Welfare; European Commission: Brussels, Belgium, 2007.

18. Harper, G.; Henson, S. Consumer Concerns about Animal Welfare and the Impact on Food Choice; EU FAIR CT98-3678; Centre for Food Economics Research, The University of Reading: Reading, UK, 2001.

19. Holm, L.; Möhl, M. The role of meat in everyday food culture: An analysis of an interview study in Copenhagen. Appetite 2000, 34, 277-283. [CrossRef] [PubMed]

20. Kennedy, O.B.; Stewart-Knox, B.J.; Mitchell, P.C.; Thurnham, D.I. Consumer perceptions of poultry meat: A qualitative analysis. Nutr. Food Sci. 2004, 34, 122-129. [CrossRef]

21. Onwezen, M.C.; van der Weele, C.N. When indifference is ambivalence: Strategic ignorance about meat consumption. Food Qual. Preference 2016, 52, 96-105. [CrossRef]

22. de Vries, M.; Bokkers, E.A.M.; Van Reenen, C.G.; Engel, B.; van Schaik, G.; Dijkstra, T.; de Boer, I.J.M. Housing and management factors associated with indicators of dairy cattle welfare. Prev. Vet. Med. 2015, 118, 80-92. [CrossRef] [PubMed]

23. Von Keyserlingk, M.A.G.; Barrientos, A.; Ito, K.; Galo, E.; Weary, D.M. Benchmarking cow comfort on North American freestall dairies: Lameness, leg injuries, lying time, facility design, and management for high-producing Holstein dairy cows. J. Dairy Sci. 2012, 95, 7399-7408. [CrossRef] [PubMed]

24. Europea Commission. Overview of Cap Reform 2014-2020. Agricultural Policy Perspectives Brief; Europea Commission: Brussels, Belgium, 2013. 
25. Granello, D.H.; Wheaton, J.E. Online data collection: Strategies for research. J. Couns. Dev. 2004, 82, $387-393$. [CrossRef]

26. Fraser, D. Understanding animal welfare. Acta Vet. Scand. 2008, 50. [CrossRef]

27. Vossler, C.A.; Kerkvliet, J. A criterion validity test of the contingent valuation method: Comparing hypothetical and actual voting behavior for a public referendum. J. Environ. Econ. Manag. 2003, 45, 631-649. [CrossRef]

28. Welfare Quality ${ }^{\circledR}$ Consortium. Welfare Quality ${ }^{\circledR}$ Assessment Protocol for Cattle; Welfare Quality ${ }^{\circledR}$ Consortium: Lelystad, The Netherlands, 2009; p. 182.

29. Field, A. Discovering Statistics Using SPSS; Sage Publications: Thousand Oaks, CA, USA, 2009.

30. Nunnally, J.C. Psychometric Theory, 2nd ed.; McGraw-Hill: New York, NY, USA, 1987.

31. Kuo, R.J.; Ho, L.M.; Hu, C.M. Integration of self-organizing feature map and K-means algorithm for market segmentation. Comput. Oper. Res. 2002, 29, 1475-1493. [CrossRef]

32. Vanhonacker, F.; Verbeke, W.; Van Poucke, E.; Tuyttens, F.A. Segmentation based on consumers' perceived importance and attitude toward farm animal welfare. Int. J. Sociol. Agric. Food 2007, 15, 91-107.

33. Pouta, E.; Heikkilä, J.; Forsman-Hugg, S.; Isoniemi, M.; Mäkelä, J. Consumer choice of broiler meat: The effects of country of origin and production methods. Food Qual. Preference 2010, 21, 539-546. [CrossRef]

34. Phillips, C.; Izmirli, S.; Aldavood, J.; Alonso, M.; Choe, B.I.; Hanlon, A.; Handziska, A.; Illmann, G.; Keeling, L.; Kennedy, M. An international comparison of female and male students' attitudes to the use of animals. Animals 2010, 1, 7-26. [CrossRef] [PubMed]

35. Kendall, H.A.; Lobao, L.M.; Sharp, J.S. Public Concern with Animal Well-Being: Place, Social Structural Location, and Individual Experience. Rural Sociol. 2006, 71, 399-428. [CrossRef]

36. Boogaard, B.K.; Bock, B.B.; Oosting, S.J.; Krogh, E. Visiting a farm: An exploratory study of the social construction of animal farming in Norway and the Netherlands based on sensory perception. Int. J. Sociol. Agric. Food 2010, 17, 24-50.

37. Diamantopoulos, A.; Schlegelmilch, B.B.; Sinkovics, R.R.; Bohlen, G.M. Can socio-demographics still play a role in profiling green consumers? A review of the evidence and an empirical investigation. J. Bus. Res. 2003, 56, 465-480. [CrossRef]

38. Vanhonacker, F.; Verbeke, W. Buying higher welfare poultry products? Profiling Flemish consumers who do and do not. Poult. Sci. 2009, 88, 2702-2711. [CrossRef] [PubMed]

39. Verbeke, W.; Vackier, I. Profile and effects of consumer involvement in fresh meat. Meat Sci. 2004, 67, 159-168. [CrossRef] [PubMed]

40. Simonson, I.; Tversky, A. Choice in context: Tradeoff contrast and extremeness aversion. J. Mark. Res. 1992, 29, 281-295. [CrossRef]

41. Tuyttens, F.A.; Vanhonacker, F.; Van Poucke, E.; Verbeke, W. Quantitative verification of the correspondence between the Welfare Quality ${ }^{\circledR}$ operational definition of farm animal welfare and the opinion of Flemish farmers, citizens and vegetarians. Livest. Sci. 2010, 131, 108-114. [CrossRef]

42. Boogaard, B.K.; Oosting, S.J.; Bock, B.B. Defining sustainability as a socio-cultural concept: Citizen panels visiting dairy farms in the Netherlands. Livest. Sci. 2008, 117, 24-33. [CrossRef]

43. Schuppli, C.A.; Von Keyserlingk, M.A.G.; Weary, D.M. Access to pasture for dairy cows: Responses from an online engagement. J. Anim. Sci. 2014, 92, 5185-5192. [CrossRef] [PubMed]

44. Miele, M. Report Concerning Consumer Perceptions and Attitudes towards Farm Animal Welfare; European Animal Welfare Platform: Brussels, Belgium, 2010.

45. Kolodinsky, J. Persistence of health labeling information asymmetry in the United States: Historical perspectives and twenty-first century realities. J. Macromark. 2012, 32, 193-207. [CrossRef]

46. Van Kleef, E.; Van Trijp, H.; Paeps, F.; Fernandez-Celemin, L. Consumer preferences for front-of-pack calories labeling. Public Health Nutr. 2008, 11, 203-213. [CrossRef] [PubMed]

47. Heleski, C.R.; Mertig, A.G.; Zanella, A.J. Assessing attitudes toward farm animal welfare: A national survey of animal science faculty members. J. Anim. Sci. 2004, 82, 2806-2814. [CrossRef] [PubMed]

48. Ingenbleek, P.T.M.; Binnekamp, M.H.A.; van Trijp, J.C.M. Betalen Voor Dierenwelzijn: Barrieres en Oplossingsrichtingen in Consumentenmarkten en Business-to-Business Markten; Landbouw Economisch Instituut (LEI): Den Haag, the Netherlands, 2006. 
49. De Graaf, S.; Van Loo, E.J.; Bijttebier, J.; Vanhonacker, F.; Lauwers, L.; Tuyttens, F.A.; Verbeke, W. Determinants of consumer intention to purchase animal-friendly milk. J. Dairy Sci. 2016, 99, 8304-8313. [CrossRef] [PubMed]

50. Müller-Lindenlauf, M.; Deittert, C.; Köpke, U. Assessment of environmental effects, animal welfare and milk quality among organic dairy farms. Livest. Sci. 2010, 128, 140-148. [CrossRef]

(c) 2016 by the authors; licensee MDPI, Basel, Switzerland. This article is an open access article distributed under the terms and conditions of the Creative Commons Attribution (CC-BY) license (http:// creativecommons.org/licenses/by/4.0/). 